\title{
Pancreatoduodenectomy with portal vein resection favors the survival time of patients with pancreatic ductal adenocarcinoma: A propensity score matching analysis
}

\author{
ZHI-BO XIE* , JI LI* , JI-CHUN GU* , CHEN JIN, CAI-FENG ZOU and DE-LIANG FU \\ Department of Pancreatic Surgery, Pancreatic Disease Institute, Huashan Hospital, \\ Shanghai Medical College, Fudan University, Shanghai 200040, P.R. China
}

Received April 7, 2019; Accepted July 18, 2019

DOI: $10.3892 / \mathrm{ol} .2019 .10822$

\begin{abstract}
Portal vein (PV) involvement is common in patients with pancreatic ductal adenocarcinoma (PDAC). To the best of our knowledge, pancreatectomy combined with PV resection (PVR) is the only radical therapy for patients with PV involvement. However, there remains a debate on whether patients with PV involvement could benefit from PVR or not. The present study aimed to compare the survival outcomes between patients receiving pancreatoduodenectomy (PD) with PVR and those receiving PD alone. A total of 377 patients with PDAC were enrolled, 138 patients with PV involvement were placed in the PVR group, while the other 239 patients were in the non-PVR group. To reduce selection bias and estimate the causal effect, 123 pairs of propensity score matched (PSM) patients were selected and compared for the survival outcomes. Before PSM, the survival of patients in the PVR group was worse compared with those in the non-PVR group (mean survival, 25.1 vs. 29.3 months; $\mathrm{P}=0.038$ ). After balancing the baseline characteristics using the PSM method, the significant survival difference between the two groups was insignificant (mean survival, 25.9 vs. 31.2 months; $\mathrm{P}=0.364$ ). Tumor stage, body mass index, serum albumin, R1 resection, lymph node metastasis, carbohydrate antigen (CA)125 and CA19-9 were significant independent prognostic factors. The incidence of serious postoperative complications was similar between the two groups. PVR is safe and effective for patients with PDAC. Patients with PV involvement could achieve the similar
\end{abstract}

Correspondence to: Dr De-Liang Fu, Department of Pancreatic Surgery, Pancreatic Disease Institute, Huashan Hospital, Shanghai Medical College, Fudan University, 12 Central Urumqi Road, Shanghai 200040, P.R. China

E-mail: surgeonfu@163.com

${ }^{*}$ Contributed equally

Key words: pancreatic ductal adenocarcinoma, pancreaticoduodenectomy, portal vein reconstruction, portal vein invasion, propensity score matching survival outcome as patients without PV involvement, through radical resection combined with PVR, without increasing the risk of serious complications.

\section{Introduction}

Pancreatic ductal adenocarcinoma (PDAC) is known as one of the most malignant types of neoplasm, with a 5-year survival rate of $<6 \%$. In addition, there is an increasing number of patients diagnosed annually with de novo $\operatorname{PDAC}(1,2)$. Although radical resection provides a chance of successful treatment, only $15-20 \%$ of patients with PDAC are candidates for radical resection at the time of diagnosis (3-5). The majority of unresectable patients present with distant metastasis and others present with tumor invasion of surrounding vessels (6).

In the past, patients with portal vein (PV) involvement were deemed unresectable because PV invasion would be a harbinger of metastatic disease and early attempts of pancreaticoduodenectomy (PD) with PV resection (PVR) were always coupled with worse survival time (211 vs. 374 days; $\mathrm{P}<0.001)(7)$. With the development of vascular reconstruction technique, PD combined with PVR has been gradually carried out for selected patients with PDAC with PV involvement (8). However, there remains a debate on whether it is worthwhile to perform PD synchronously with PVR knowing that local recurrence is not common in patients with PV invasion (9). A number of studies demonstrated that PD with PVR provided no significant survival benefit at the expense of higher rates of morbidity and mortality (10-12), while others argued that PD with PVR was safe and feasible and could offer improved survival outcomes (13-16).

A recent systemic review reported that the median overall survival (OS) time was worse in patients with PVR (14.3 vs. 19.5 months) and the postoperative complication rate was higher (odds ratio, 1.34; $\mathrm{P}=0.03$ ) (17). However, more patients in the PD+PVR group had larger tumors, higher tumor grades, more plexus invasion and greater lymph node (LN) metastasis (18-20). In addition, there was a notable difference in baseline clinical characteristics between patients with and without PVR (20). Due to the poorer clinical characteristics, patients with PVR usually have worse long-term prognosis (20). 
Given this dilemma, propensity score matching (PSM), which is the conditional probability of assignment to a particular treatment given a vector of observed covariate (21), has been widely used to balance the baselines between the experimental group and control group $(22,23)$ for the sake of reducing selection bias and identifying the causal effect $(21,24)$.

It was demonstrated in our previous study that PVR could significantly improve the OS of patients with PV involvement as compared with chemotherapy or surgical bypass (25). However, comparisons between patients with or without PVR, to the best of our knowledge, have not been reported. The aim of the present study was to compare the survival outcomes between patients with or without PVR by using the PSM method. This was done to determine whether patients with PV involvement could achieve the same survival benefit from PVR as patients without PV involvement, in order to verify the efficacy and safety of PVR.

\section{Patients and methods}

Inclusion and exclusion criteria. The inclusion criteria for the patients enrolled in the present study were as follows: i) Age $>18$ years; ii) patients diagnosed with histopathologically confirmed resectable PDAC; and iii) patients who underwent PD with or without PVR. The exclusion criteria were as follows: i) Patients with severe medical comorbidities and other uncontrolled malignancies; and ii) patients with perior intra-operative evidence of distant metastasis and arterial involvement. Before PSM, 377 patients (PVR group, $n=138$; non-PVR group, $n=239$ ) from Huashan Hospital (Shanghai, China) were enrolled in the present study from January 2011 to December 2013. Among which, 231 patients were males (mean age, 61.8 \pm 8.7 years; range, $34-84$ years) and 146 patients were females (mean age, $62.3 \pm 8.8$ years; range, 29-84 years). After PSM, 246 patients (PVR group, $n=123$; non-PVR group, $\mathrm{n}=123$ ) from Huashan Hospital (Shanghai, China) were enrolled into the present study. Among which, 151 patients were males (mean age, 62.0 \pm 9.2 years; range, 35-84 years) and 95 patients were females (mean age, 62.8 \pm 9.7 years; range, $29-83$ years).

Tumor stage was assessed pathologically according to the Tumor-Node-Metastasis (TNM) classification system published by the American Joint Committee on Cancer, 8th edition (26). This study was approved and performed in accordance with the Declaration of Helsinki and the Clinical Research Ethics Committee of Huashan Hospital. All patients signed informed consent for surgical treatment and pathological examinations.

Preoperative detection and evaluation. Ultrasonography, computed tomography (CT), MRI, positron emission tomography-CT (PET-CT) and endoscopic sonography were performed to evaluate local tumor extension and metastasis. A high suspicion of PV involvement based on preoperative imaging, such as CT or MRI, was determined. Nevertheless, the surgeon's intraoperative visual judgments were also of great importance to determine the possibility of PV involvement. Patient demographics [serum leukocyte count, serum alanine aminotransferase (ALT), total bilirubin (TBil), albumin (ALB), body mass index (BMI), serum carbohydrate antigen
(CA)125 and CA19-9], tumor characteristics, intra-operative parameters and patient survival were compared between the two groups.

Surgical procedures. Patients with resectable primary tumors and preoperative evaluation of $\mathrm{PV}$ involvement (27) were divided into a PD+PVR group and a PD group. All patients enrolled in this study underwent detailed preoperative examination, including both blood tests and imageological examinations (CT, MRI or PET-CT). Patients with suspected metastasis were confirmed by pathological evidence (biopsy or operation) and were excluded from this study. During the operation, the surgeon's own visual judgments and intraoperative ultrasound was used to detect remote metastasis. Patients with any extra-pancreatic metastasis, which were not detected by preoperative PET-CT scanning, were also excluded from this study. Patients with PV involvement, but without possibility of reconstruction (multiple branch involvement), underwent surgical bypass (SB) procedure based on intra-operative judgment of the surgeon, and were also excluded from this study.

In the PD group, patients underwent classical PD. In the PD+PVR group, patients with PV involvement underwent radical resection of PDAC and PVR. PVR was carried out en-bloc as primary closure of the vein, and reconstructed with ePTFE vascular grafts (Bard Peripheral Vascular, Inc.).

Follow-up observation and complications. During the follow-up period (the last follow-up date was December 2018), all patients were followed up for $\mathrm{CT}$ and blood tests, and patients with PVR required an additional ultrasound to detect patency of the artificial grafts. Patients were followed up monthly postoperatively for the first 6 months, then every 3-6 months thereafter. All patients in PVR group were administrated aspirin (100 mg a day) and received ultrasound examinations postoperatively. OS time was the primary outcome of this study. Postpancreatectomy hemorrhage (PPH), postoperative pancreatic fistula (POPF), chylous fistula and delayed gastric emptying (DGE) were defined according to International Study Group of Pancreatic Surgery (28-31). In the present study, all patients died from disease.

PSM analysis. There were statistically significant differences in the baseline characteristics between the two groups, which would affect the outcome of analysis. For continuous data, differences between the two groups were analyzed using the independent Student's t-test, and a $\chi^{2}$ test was used for categorical variables. PSM was utilized to balance the baseline characteristics between the two groups, in order to reduce the risk of selection bias and mimic a controlled randomized trial. A logistic regression model was used to estimate PSM based on age, sex, BMI, leukocyte, ALT, TBil, ALB, CA125, CA19-9, tumor stage, LN metastasis and tumor size. One-to-one matching without replacement conducted by a 0.1 caliper matching on the estimated propensity score generated 123 matched PVR and non-PVR units (32).

Statistical analysis. All demographic and clinicopathological data were collected in the computer database of Huashan Hospital and analyzed statistically using SPSS 23.0 (IBM, 
Corp.). In the case of continuous data, differences between the two groups were analyzed through the independent Student's $\mathrm{t}$-test, and a $\chi^{2}$ test was used for categorical variables. Survival curves were established using the Kaplan-Meier method and compared with a log-rank test. Continuous data were reported as mean \pm standard error. Significant risk factors were first identified using univariate logistic regression, after which the significant univariate factors were further examined using multivariate analysis. The outcomes were presented using hazard ratios (HRs) and associated $95 \%$ confidence intervals (CIs). A two-sided $\mathrm{P}<0.05$ was considered to indicate a statistically significant difference.

\section{Results}

Demographic and clinicopathological parameters of the included patients before PSM. Between 2011 and 2013, there were 138 patients who underwent PD+PVR and the remaining 239 received PD without PVR. Patients in the PD+PVR group exhibited more tumor stage II patients $(\mathrm{P}<0.001)$, smaller BMIs $(\mathrm{P}=0.015)$, significantly higher $\mathrm{CA} 19-9$ levels $(\mathrm{P}=0.040)$, significantly lower $\mathrm{CA} 125$ levels $(\mathrm{P}=0.010)$, larger tumor sizes $(\mathrm{P}<0.001)$, longer operating durations $(\mathrm{P}<0.001)$ and more intraoperative blood loss $(\mathrm{P}<0.001)$ (Table I).

Survival analysis before PSM analysis. Multivariate Cox regression model showed that advanced tumor stages, lower BMI levels, LN metastasis, lower ALB levels, higher CA125 and CA19-9 levels were independent prognostic factors (Table II).

Survival analysis revealed that patients in the PVR group had significantly worse survival outcomes compared with patients in the non-PVR group (mean survival, 25.1 vs. 29.3 months; $\mathrm{P}=0.038$; Fig. 1). A number of other factors associated with OS, such as TNM stage, BMI, ALB and LN metastasis, were further analyzed as indicated in Fig. 1.

Logistic regression analysis identified two risk factors that could predict PV invasion: advanced tumor stages (HR, 20.439; 95\% CI, 4.166-100.271; $\mathrm{P}<0.001)$ and higher CA19-9 levels (HR, 6.608; 95\% CI, 2.064-21.154; $\mathrm{P}=0.001$ ).

Demographic and clinicopathological parameters of the included patients after PSM. A total of 123 matched pairs of patients from the PD+PVR and non-PVR groups were confirmed via PSM based on age, sex BMI, leukocyte, ALT, TBil, ALB, CA125, CA19-9, tumor stage, LN metastasis and tumor size. After PSM, a number of factors, which may imply patients' pre-operative general status and have an effect on survival, were balanced including age, BMI, ALB, CA125, CA19-9, tumor stage, LN metastasis and tumor size (Table I).

Survival analysis after PSM. Multivariate Cox regression model showed that advanced tumor stages, lower BMI levels, $\mathrm{R} 1$ resection (microscopic positive margin), LN metastasis, lower ALB levels, higher CA125 and CA19-9 levels were independent prognostic factors (Table II).

Survival analysis showed that the survival outcome of patients in the PD+PVR group was similar to that of patients in the non-PVR group (mean survival, 25.9 vs. 31.2 months;
$\mathrm{P}=0.364$; Fig. 2). Other factors such as TNM stage, LN metastasis, BMI, ALB, R1 resection, CA125 and CA19-9 associated with OS were further analyzed and were shown in Fig. 2.

Logistic regression analysis also identified advanced tumor stage (HR, 17.827; 95\% CI, 3.627-87.627; P<0.001) and higher CA19-9 levels (HR, 6.913; 95\% CI, 2.124-22.503; $\mathrm{P}=0.001$ ) as the same two risk factors predicting PV invasion.

Subgroup analysis in the PD+PVR group. Regardless to prior or latter PSM, patients with PV invasion, advanced tumor stage, R1 resection, lower BMI levels, lower ALB levels, LN metastasis, lower CA125 and CA19-9 levels had poorer prognostic outcomes (Table SI; Figs. S1 and S2).

Subgroup analysis in non-PVR group. The results still indicated that patients with advanced tumor stage, R1 resection, LN metastasis, lower CA125 and CA19-9 levels had poorer prognostic outcomes, regardless to prior or latter PSM. Lower ALB levels and lower BMI did not indicate a worse prognosis in the non-PVR group (Table SII; Figs. S3 and S4).

Postoperative complications. Patients in the PD+PVR group did not have a significantly higher overall complication rate or more severe complications compared with patients in the non-PVR group (all $\mathrm{P}>0.05$ ). The postoperative complications in PD+PVR and non-PVR groups were combined and the most frequent complication was POPF $(n=220 ; 58.4 \%)$. Other complications were chylous fistula in 10 patients $(2.7 \%)$, DGE in 44 patients $(11.7 \%)$, PPH in 22 patients $(5.8 \%)$, wound infection in 47 patients $(12.5 \%)$, pleural effusion in 67 patients (17.8\%) and abdominal infection in 11 patients (2.9\%) before PSM. After PSM, the most frequent combined complication remained POPF $(\mathrm{n}=133 ; 54.1 \%)$, and other complications were chylous fistula in 3 patients (1.2\%), DGE in 27 patients $(11.0 \%)$, PPH in 9 patients $(3.7 \%)$, wound infection in 25 patients $(10.2 \%)$, pleural effusion in 44 patients $(17.9 \%)$ and abdominal infection in 9 patients (3.7\%) (Table III). There was no 30-day mortality indicated in either group. Furthermore, no graft infection, thrombosis, or serious graft-related complication has been reported in patients in the PVR group.

\section{Discussion}

Growing evidence has demonstrated that $\mathrm{PV}$ resection is safe for the treatment of patients with borderline resectable PDAC (33-35). PD combined with PVR is the only radical therapy for PDAC patients with PV involvement at present (7). Our previous study demonstrated that patients with radical resection of PDAC and PVR had significantly improved survival compared with patients with chemotherapy or SB alone (25). However, other studies drew controversial conclusions after comparing the survival between patients with PVR and patients undergoing pancreatectomy alone (7,16,36-44). This discrepancy between different studies may mainly be due to huge heterogenicity of patients between the study and control groups. In the present study, the PSM method was used to balance the baseline characteristics between the PVR and non-PVR groups, and it was indicated that patients with PD combined with PVR could achieve the same survival outcome as patients without PVR. 


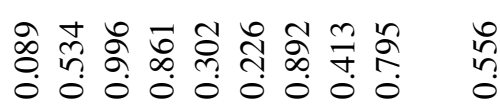

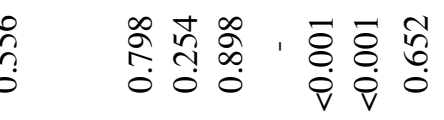

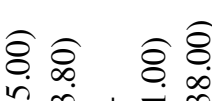
$\approx$ กิ่

范

๙

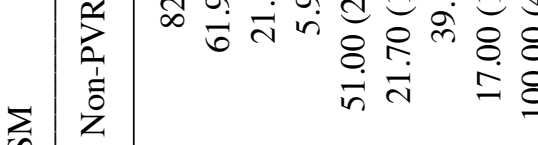

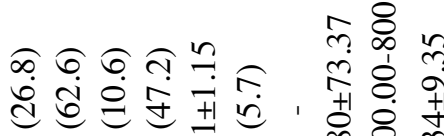

$m \leqslant 9$ 舟

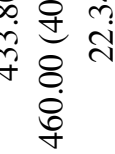

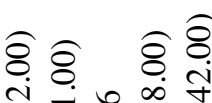

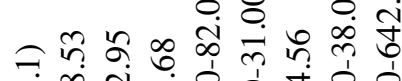

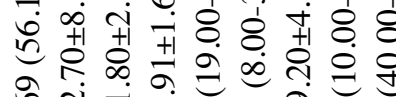

बें

焉

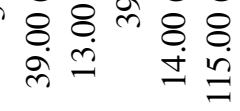

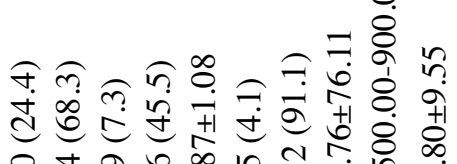

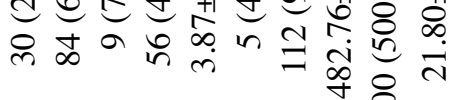

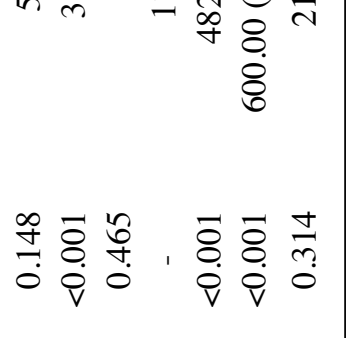

旁

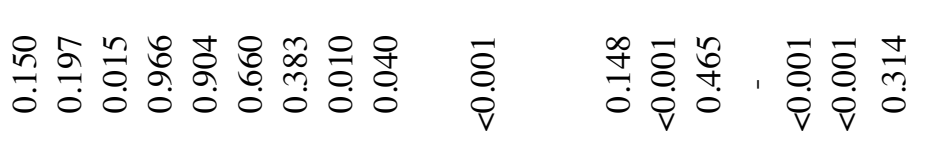

䓂

至

(1)

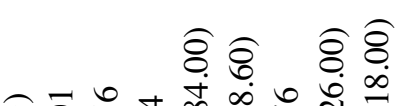

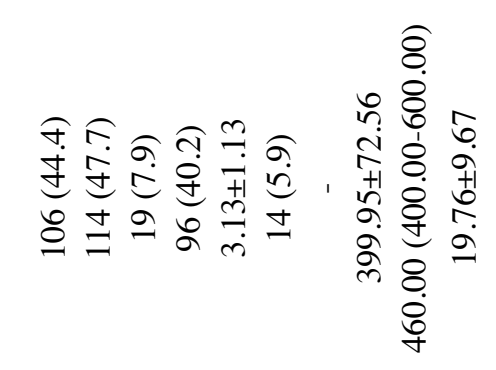

过茾

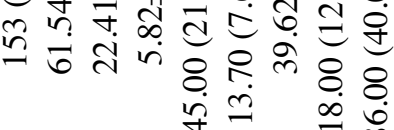

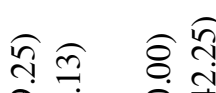

กิ่

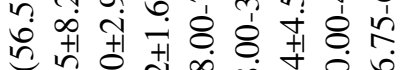

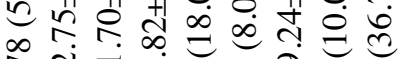

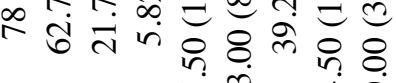

के

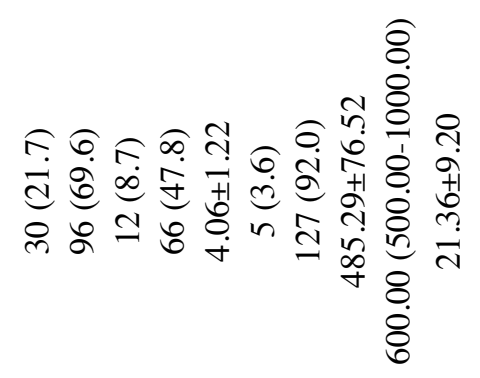

$\frac{0}{8}$

.

$-$

度 
Table II. Multivariate regression analysis of prognostic factors.

\begin{tabular}{|c|c|c|c|c|c|c|}
\hline \multirow[b]{3}{*}{ Risk factors } & \multicolumn{3}{|c|}{ Before PSM } & \multicolumn{3}{|c|}{ After PSM } \\
\hline & \multicolumn{3}{|c|}{ Multivariate regression analysis } & \multicolumn{3}{|c|}{ Multivariate regression analysis } \\
\hline & HR & $95 \% \mathrm{CI}$ & P-value & HR & $95 \% \mathrm{CI}$ & P-value \\
\hline \multicolumn{7}{|l|}{ Therapy } \\
\hline $\begin{array}{l}\text { PVR } \\
\text { Non-PVR }\end{array}$ & 1.084 & $0.831-1.415$ & 0.551 & - & - & - \\
\hline \multicolumn{7}{|l|}{ TNM stage } \\
\hline $\begin{array}{l}\text { Stage I } \\
\text { Stage II } \\
\text { Stage III }\end{array}$ & 1.643 & $1.214-2.225$ & 0.001 & 1.912 & $1.319-2.771$ & 0.001 \\
\hline \multicolumn{7}{|l|}{$\mathrm{BMI}, \mathrm{kg} / \mathrm{m}^{2}$} \\
\hline $\begin{array}{l}<18.5 \\
\geq 18.5\end{array}$ & 0.652 & $0.436-0.974$ & 0.037 & 0.601 & $0.388-0.931$ & 0.023 \\
\hline \multicolumn{7}{|l|}{$\mathrm{R} 1$ resection } \\
\hline $\begin{array}{l}\text { No } \\
\text { Yes }\end{array}$ & 1.685 & $0.957-2.966$ & 0.071 & 1.955 & $1.018-3.755$ & 0.044 \\
\hline \multicolumn{7}{|l|}{ LN metastasis } \\
\hline $\begin{array}{l}\text { Yes } \\
\text { No }\end{array}$ & 0.646 & $0.465-0.898$ & 0.009 & 0.642 & $0.440-0.936$ & 0.021 \\
\hline \multicolumn{7}{|l|}{ ALB, $g / 1$} \\
\hline $\begin{array}{l}<35 \\
\geq 35\end{array}$ & 0.568 & $0.371-0.868$ & 0.009 & 0.569 & $0.350-0.923$ & 0.022 \\
\hline \multicolumn{7}{|l|}{ CA125 U/ml } \\
\hline $\begin{array}{l}<35 \\
\geq 35\end{array}$ & 1.475 & $1.082-2.011$ & 0.014 & 1.49 & $1.038-2.139$ & 0.031 \\
\hline \multicolumn{7}{|l|}{ CA19-9 U/ml } \\
\hline $\begin{array}{l}<37 \\
37-200\end{array}$ & 1.708 & $1.396-2.089$ & $<0.001$ & 1.485 & $1.178-1.872$ & 0.001 \\
\hline$>200$ & & & & & & \\
\hline
\end{tabular}

BMI, body mass index; HR, hazard ratio; CI, confidence interval; TNM, Tumor-Node-Metastasis; PSM, propensity score matched; PVR, portal vein resection; ALB, albumin; CA125, carbohydrate antigen 125; CA19-9, carbohydrate antigen 19-9; LN, lymph node.

In patients with PV invasion, tumor cells are more likely to invade the host stroma, penetrate blood vessels and enter the circulation to produce metastasis by forming new colonies in distant organs (45). We hypothesize that this may be the reason for patients with PVR to have significantly worse survival outcomes. In the present study, it was indicated that before PSM, patients in the PVR group had poor survival outcomes compared with patients in the non-PVR group. However, it was identified that the poor prognosis may be due to the fact that patients in the PVR group were accompanied with higher CA19-9 levels, advanced tumor stages and bigger tumor sizes. All these factors imply that patients in the PVR group were at a more advanced stage of the disease, and certainly with a worse survival outcome $(\mathrm{P}=0.038)$. In order to eliminate selection bias between the two groups, the PSM method was used. After PSM, although patients in the PVR group still had longer operation durations and more blood loss, the other factors were balanced as expected. The patients in the PVR group achieved the same survival outcomes as the patients in the non-PVR group $(\mathrm{P}=0.364)$, indicating that heterogeneity of the baseline characteristics between the two groups did have a potential effect on survival. Through PSM, the current study balanced the heterogeneity and provided a reliable conclusion.

Other than the unbalanced baseline characteristics, we hypothesize that the method of resection and reconstruction may also have an effect on survival. In the present study, the patients in the PVR group underwent radical resection of the primary PDAC, PV resection and reconstruction with artificial blood vessels (ePTFE vascular grafts). For PV reconstruction, self-anastomosis, autogenous and allograft vessel grafts were used in different circumstances (25). In the current study, artificial blood vessels (ePTFE vascular grafts) were used for reconstruction, in order to achieve the optimum tumor-free 

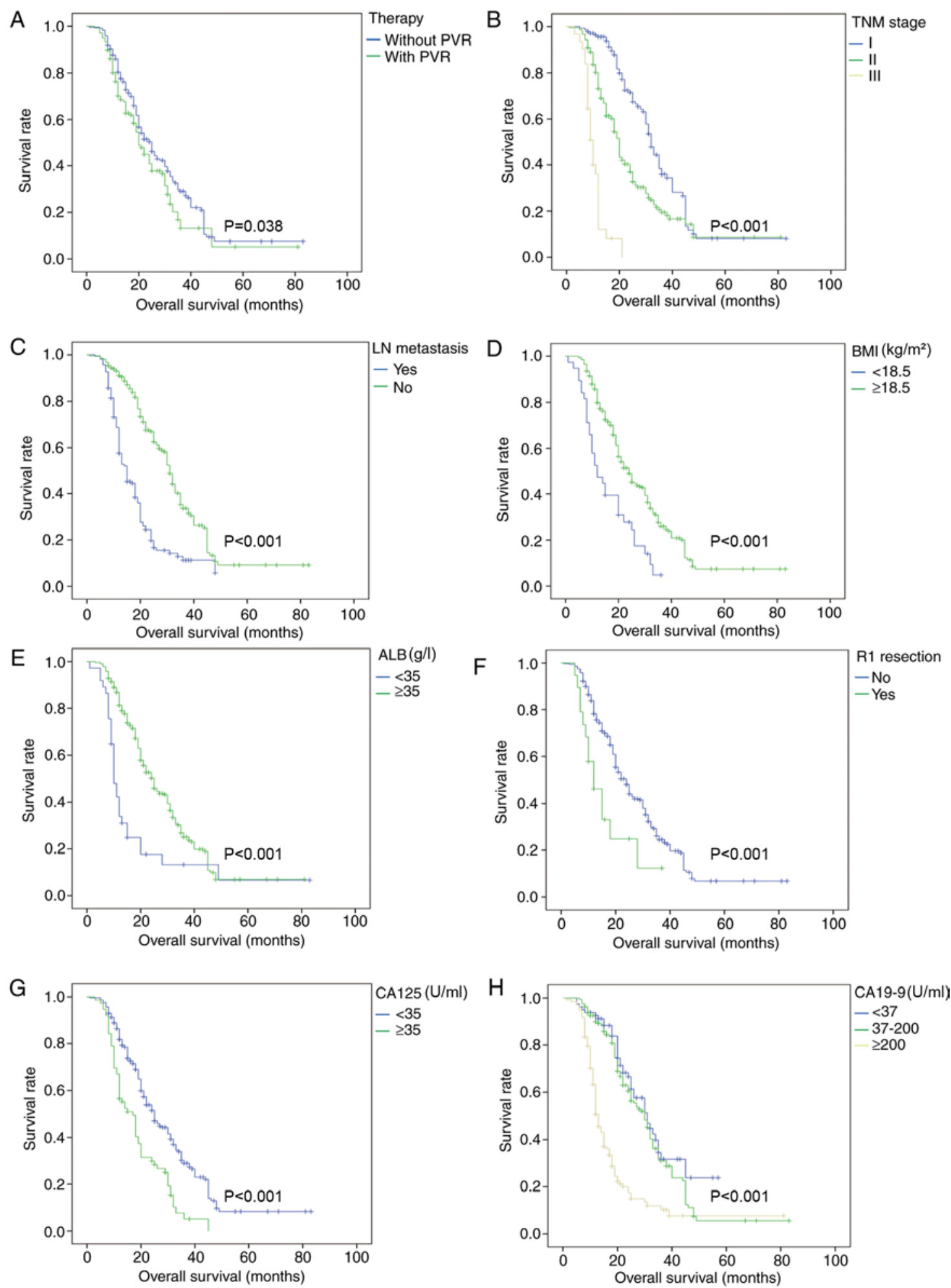

Figure 1. Overall survival curves before propensity score matching. Survival analysis was conducted in all enrolled patients for various factors, including (A) therapy, (B) TNM stage, (C) lymph node metastasis, (D) BMI ( $\mathrm{kg} / \mathrm{m}^{2}$ ), (E) ALB (g/l), (F) R1 resection (microscopic positive margin), (G) CA125 (U/ml) and $(\mathrm{H})$ CA19-9 (U/ml) before propensity score matching. PVR, portal vein resection; TNM, Tumor-Node-Metastasis; BMI, body mass index; ALB, albumin; CA125, carbohydrate antigen 125; CA19-9, carbohydrate antigen 19-9; LN, lymph node.

margin. Notably, initial literature research demonstrated that all studies reporting that patients with PVR, who suffered significantly poor survival outcomes, were actually studies reporting that positive surgical margin rate of patients with PVR, who underwent self-anastomosis for PV reconstruction, was relatively high $(30-50 \%)(46-48)$. In the present study, the $\mathrm{R} 1$ resection rate was $3.6 \%$ in the PVR group compared with $5.9 \%$ in the non-PVR group $(\mathrm{P}=0.465)$. This lower $\mathrm{R} 1$ resection rate may to some extent be due to the artificial blood vessels. With the artificial blood vessels, the tension of the reconstructed PV and the length of resected PV were no longer a problem for surgeons during the operation, therefore securing 
A
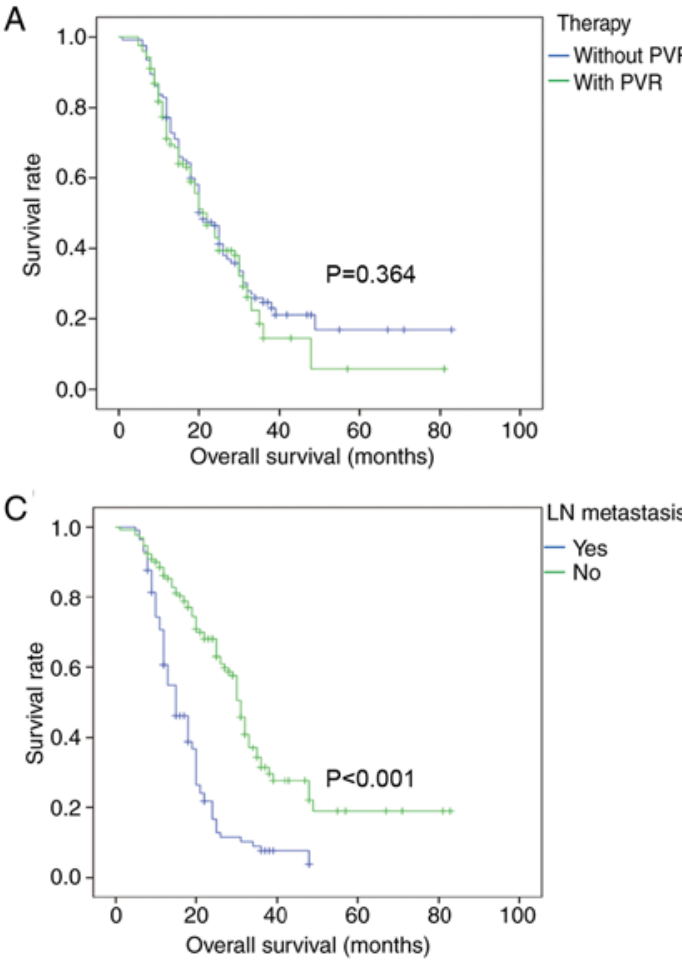

E
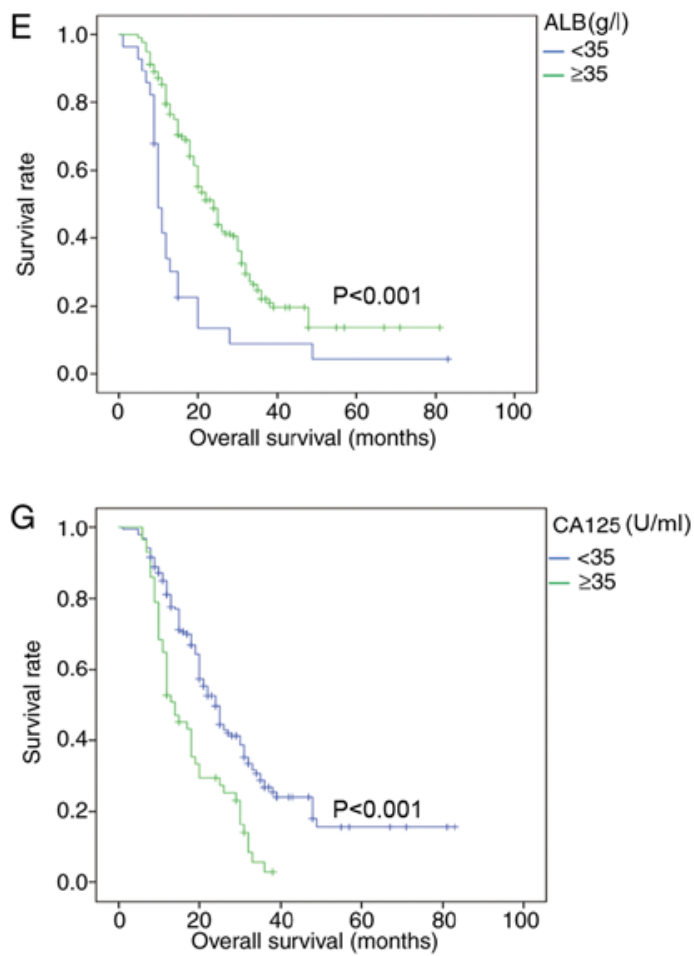
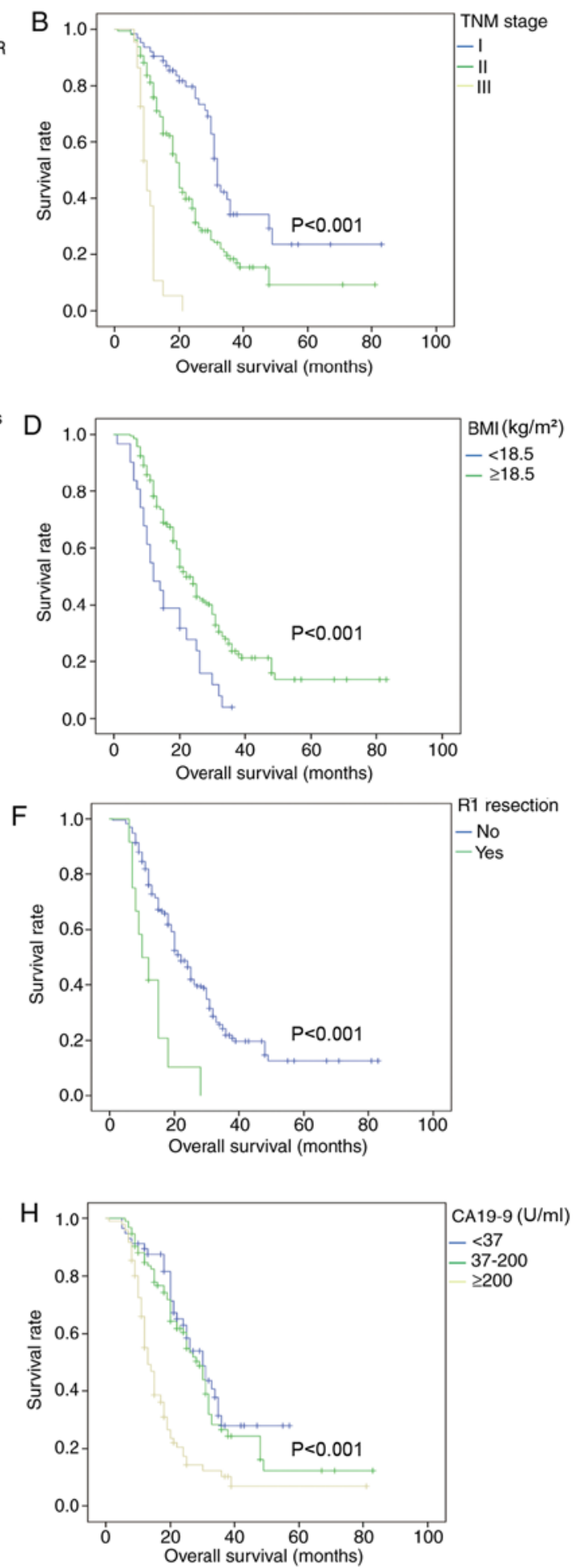

Figure 2. Overall survival curves after propensity score matching. Survival analysis was conducted in all enrolled patients for various factors, including (A) therapy, (B) TNM stage, (C) lymph node metastasis, (D) BMI (kg/m²), (E) ALB (g/l), (F) R1 resection (microscopic positive margin), (G) CA125 (U/ml) and (H) CA19-9 (U/ml) after propensity score matching. PVR, portal vein resection; TNM, Tumor-Node-Metastasis; BMI, body mass index; ALB, albumin; CA125, carbohydrate antigen 125; CA19-9, carbohydrate antigen 19-9; LN, lymph node.

the radical resection of the primary PDAC and invaded PV. However, this study did not compare the benefits between autografts and allografts and therefore further multiple-center studies are required.

The biggest concern for the use of PVR is safety. The complications between patients with PVR and patients with no PVR were compared and it was indicated that regardless of PSM status, there was no significant difference in the complication rate in terms of POPF, chylous fistula, DGE, $\mathrm{PPH}$, wound infection, pleural effusion and abdominal infection between the two groups. Therefore, this study suggested that PVR did not increase the incidence of serious surgical complications. Previous studies have reported that the use of artificial vascular grafts may run a potential risk of infection 


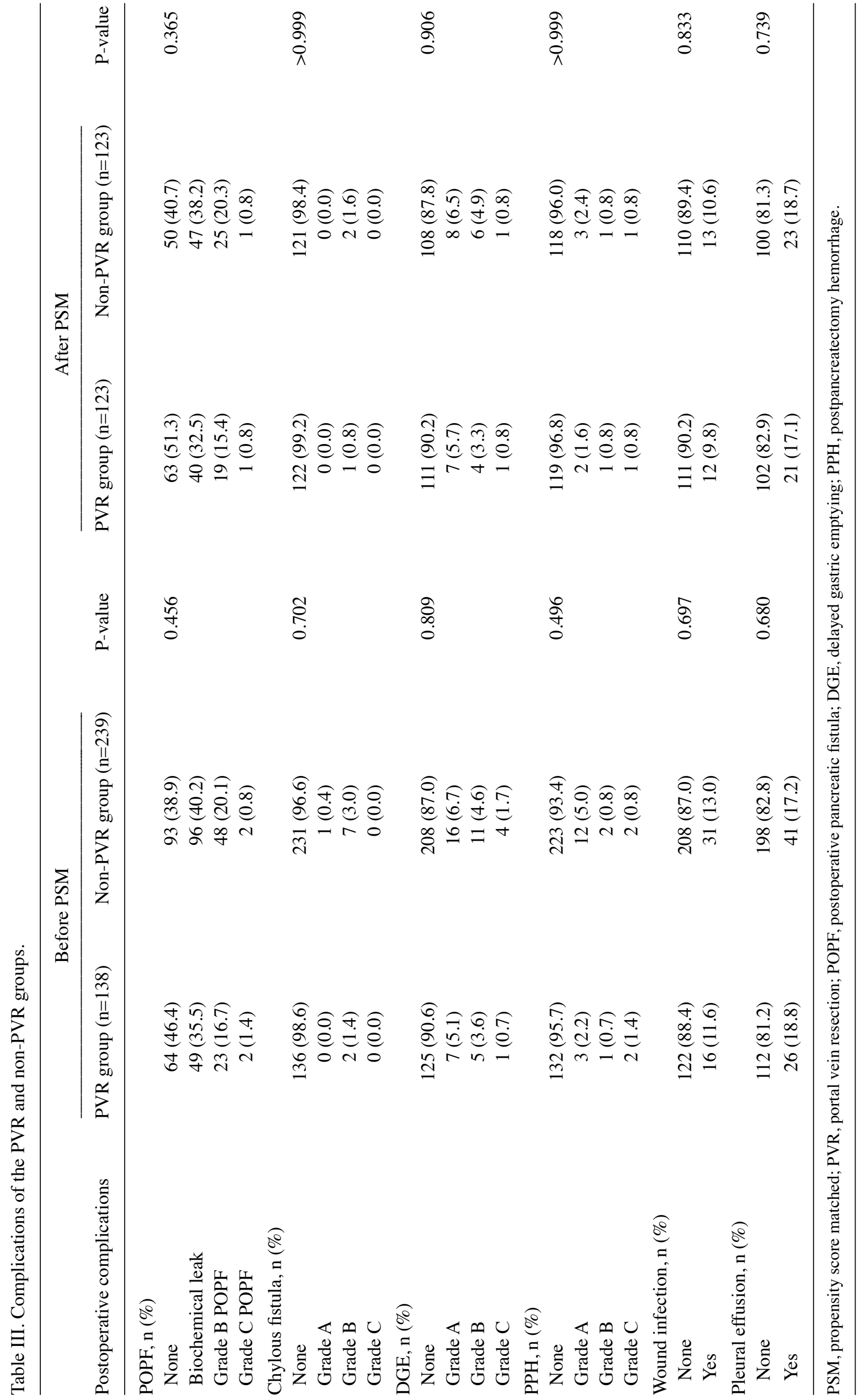


and thrombosis $(49,50)$. In the present study, all patients in PVR group were administrated aspirin and received ultrasound examinations. To the best of our knowledge, no graft infection, thrombosis, or serious graft-related complication has been reported. The aforementioned suggests that PD combined with PVR and reconstruction with artificial blood vessels is a safe and viable option for the treatment of patients with PV invasion.

The biggest limitation of the current study was its retrospective nature, although attempts were made to reduce or eliminate the bias by utilizing the PSM method and enlarging the sample size. It was indicated that the baseline characteristics were well balanced after using the PSM method. To the best of our knowledge, there is no prospective study design dealing with this issue and therefore the present study is the only one to conduct a comparison between patients with or without PVR using the PSM method. Secondly, no comparison between patients with autograft and allograft was conducted in the present study. Future multi-center research will focus on such clinical experience and perform respective comparisons.

In conclusion, PVR may offer patients with PV involvement the same survival outcome as patients without PV involvement, without increasing the incidence of serious complications. PVR is a safe and viable option for patients with PDAC and is effective for patients with PDAC with suspected PV invasion.

\section{Acknowledgements}

Not applicable.

\section{Funding}

The present study was funded by grants from the National Natural Science Foundation of China (grant no. 81472221) and Clinical Key Projects of the National Health and Family Planning (grant no. Oncology 2013-2015).

\section{Availability of data and materials}

All datasets generated and/or analyzed during this study are included in this article and its supplementary information file.

\section{Authors' contributions}

ZBX and DLF conceived and designed the study. ZBX, JCG, JL and DLF provided administrative support. JCG, JL, CFZ, CJ and DLF provided materials and/or patients for the study. ZBX, JCG, CFZ, CJ and JL were responsible for the collection and assembly of data. JCG, CFZ, CJ and JL conducted data analysis and interpretation. ZBX, JCG and JL were responsible for manuscript writing. All authors have read and approved the version of the manuscript. All authors agree to be accountable for all aspects of the work in ensuring that questions related to the accuracy or integrity of any part of the work are appropriately investigated and resolved.

\section{Ethics approval and consent to participate}

This study was approved by the Clinical Research Ethics Committee of Huashan Hospital (Shanghai, China). All patients provided written informed consent to voluntarily donate their clinical data and follow-up data for research-related purposes.

\section{Patient consent for publication}

Not applicable.

\section{Competing interests}

The authors declare that they have no competing interests.

\section{References}

1. Chen W, Zheng R, Baade PD, Zhang S, Zeng H, Bray F, Jemal A, $\mathrm{Yu}$ XQ and He J: Cancer statistics in China, 2015. CA Cancer J Clin 66: 115-132, 2016.

2. Kamisawa T, Wood LD, Itoi T and Takaori K: Pancreatic cancer. Lancet 388: 73-85, 2016.

3. Winter JM, Cameron JL, Campbell KA, Arnold MA, Chang DC, Coleman J, Hodgin MB, Sauter PK, Hruban RH, Riall TS, et al: 1423 pancreaticoduodenectomies for pancreatic cancer: A single-institution experience. J Gastrointest Surg 10: 1199-1211, 2006.

4. Hidalgo M: Pancreatic cancer. N Engl J Med 362: 1605-1617, 2010.

5. Han SS, Park SJ, Kim SH, Cho SY, Kim YK, Kim TH, Lee SA, Woo SM, Lee WJ and Hong EK: Clinical significance of portal-superior mesenteric vein resection in pancreatoduodenectomy for pancreatic head cancer. Pancreas 41: 102-106, 2012.

6. Zhang XM, Fan H, Kou JT, Zhang XX, Li P, Dai Y and He Q: Resection of portal and/or superior mesenteric vein and reconstruction by using allogeneic vein for pT3 pancreatic cancer. J Gastroenterol Hepatol 31: 1498-1503, 2016.

7. Allema JH, Reinders ME, van Gulik TM, van Leeuwen DJ, de Wit LT, Verbeek PC and Gouma DJ: Portal vein resection in patients undergoing pancreatoduodenectomy for carcinoma of the pancreatic head. Br J Surg 81: 1642-1646, 1994.

8. Tseng JF, Raut CP, Lee JE, Pisters PW, Vauthey JN, Abdalla EK, Gomez HF, Sun CC, Crane CH, Wolff RA and Evans DB: Pancreaticoduodenectomy with vascular resection: Margin status and survival duration. J Gastrointest Surg 8: 935-950, 2004.

9. Müller SA, Hartel M, Mehrabi A, Welsch T, Martin DJ, Hinz U, Schmied BM and Büchler MW: Vascular resection in pancreatic cancer surgery: Survival determinants. J Gastrointest Surg 13: 784-792, 2009.

10. Castleberry AW, White RR, De La Fuente SG, Clary BM, Blazer DG III, McCann RL, Pappas TN, Tyler DS and Scarborough JE: The impact of vascular resection on early postoperative outcomes after pancreaticoduodenectomy: An analysis of the American College of Surgeons National Surgical Quality Improvement Program database. Ann Surg Oncol 19: 4068-4077, 2012.

11. Worni M, Castleberry AW, Clary BM, Gloor B, Carvalho E, Jacobs DO, Pietrobon R, Scarborough JE and White RR: Concomitant vascular reconstruction during pancreatectomy for malignant disease: A propensity score-adjusted, population-based trend analysis involving 10,206 patients. JAMA Surg 148: 331-338, 2013.

12. Roch AM, House MG, Cioffi J, Ceppa EP, Zyromski NJ, Nakeeb A and Schmidt CM: Significance of portal vein invasion and extent of invasion in patients undergoing pancreatoduodenectomy for pancreatic adenocarcinoma. J Gastrointest Surg 20: 479-487, 2016.

13. Zhou Y,Zhang Z, Liu Y,Li B and Xu D: Pancreatectomy combined with superior mesenteric vein-portal vein resection for pancreatic cancer: A meta-analysis. World J Surg 36: 884-891, 2012.

14. Turrini O, Ewald J, Barbier L, Mokart D, Blache JL and Delpero JR: Should the portal vein be routinely resected during pancreaticoduodenectomy for adenocarcinoma? Ann Surg 257: 726-730, 2013

15. Selvaggi F, Mascetta G, Daskalaki D, dal Molin M, Salvia R, Butturini G, Cellini C and Bassi C: Outcome of superior mesenteric-portal vein resection during pancreatectomy for borderline ductal adenocarcinoma: Results of a prospective comparative study. Langenbecks Arch Surg 399: 659-665, 2014. 
16. Ravikumar R, Sabin C, Abu Hilal M, Bramhall S, White S, Wigmore S, Imber CJ and Fusai G; UK Vascular Resection in Pancreatic Cancer Study Group: Portal vein resection in borderline resectable pancreatic cancer: A United Kingdom multicenter study. J Am Coll Surg 218: 401-411, 2014.

17. Giovinazzo F and Turri G: Meta-analysis of benefits of portal-superior mesenteric vein resection in pancreatic resection for ductal adenocarcinoma. Br J Surg 103: 179-191, 2016.

18. Capussotti L, Massucco P, Ribero D, Vigano L, Muratore A and Calgaro M: Extended lymphadenectomy and vein resection for pancreatic head cancer: Outcomes and implications for therapy. Arch Surg 138: 1316-1322, 2003.

19. Siriwardana HP and Siriwardena AK: Systematic review of outcome of synchronous portal-superior mesenteric vein resection during pancreatectomy for cancer. Br J Surg 93: 662-673, 2006.

20. Kaneoka Y, Yamaguchi A and Isogai M: Portal or superior mesenteric vein resection for pancreatic head adenocarcinoma: Prognostic value of the length of venous resection. Surgery 145: 417-425, 2009

21. Rosenbaum PR and Rubin DB: The central role of the propensity score in observational studies for causal effects. Biometrika 70 41-55, 1983.

22. Ruzzenente A, Guglielmi A, Sandri M, Campagnaro T, Valdegamberi A, Conci S, Bagante F, Turcato G, D'Onofrio M and Iacono C: Surgical resection versus local ablation for HCC on cirrhosis: Results from a propensity case-matched study. J Gastrointest Surg 16: 301-311, 2012.

23. Guo Z, Zhong JH, Jiang JH, Zhang J, Xiang BD and Li LQ: Comparison of survival of patients with BCLC stage A hepatocellular carcinoma after hepatic resection or transarterial chemoembolization: A propensity score-based analysis. Ann Surg Oncol 21: 3069-3076, 2014.

24. Zhong JH, Ke Y, Gong WF, Xiang BD, Ma L, Ye XP, Peng T, Xie GS and Li LQ: Hepatic resection associated with good survival for selected patients with intermediate and advanced-stage hepatocellular carcinoma. Ann Surg 260: 329-340, 2014.

25. Xie ZB, Gu JC, Zhang YF, Yao L, Jin C, Jiang YJ, Li J, Yang F, Zou CF and Fu DL: Portal vein resection and reconstruction with artificial blood vessels is safe and feasible for pancreatic ductal adenocarcinoma patients with portal vein involvement: Chinese center experience. Oncotarget 8: 77883-77896, 2017.

26. Chun YS, Pawlik TM and Vauthey JN: 8th edition of the AJCC cancer staging manual: Pancreas and hepatobiliary cancers. Ann Surg Oncol 25: 845-847, 2018.

27. Nakao A, Harada A, Nonami T, Kaneko T, Inoue S and Takagi H: Clinical significance of portal invasion by pancreatic head carcinoma. Surgery 117: 50-55, 1995.

28. Wente MN, Veit JA, Bassi C, Dervenis C, Fingerhut A, Gouma DJ, Izbicki JR, Neoptolemos JP, Padbury RT, Sarr MG, et al: Postpancreatectomy hemorrhage (PPH): An International Study Group of Pancreatic Surgery (ISGPS) definition. Surgery 142: 20-25, 2007.

29. Besselink MG, van Rijssen LB, Bassi C, Dervenis C, Montorsi M, Adham M, Asbun HJ, Bockhorn M, Strobel O, Büchler MW, et al: Definition and classification of chyle leak after pancreatic operation: A consensus statement by the International Study Group on pancreatic surgery. Surgery 161: 365-372, 2017.

30. Wente MN, Bassi C, Dervenis C, Fingerhut A, Gouma DJ, Izbicki JR, Neoptolemos JP, Padbury RT, Sarr MG, Traverso LW, et al: Delayed gastric emptying (DGE) after pancreatic surgery: A suggested definition by the International Study Group of Pancreatic Surgery (ISGPS). Surgery 142: 761-768, 2007

31. Bassi C, Marchegiani G, Dervenis C, Sarr M, Abu Hilal M, Adham M, Allen P, Andersson R, Asbun HJ, Besselink MG, et al: The 2016 update of the International Study Group (ISGPS) definition and grading of postoperative pancreatic fistula: 11 years after. Surgery 161: 584-591, 2017.

32. Austin PC, Grootendorst P and Anderson GM: A comparison of the ability of different propensity score models to balance measured variables between treated and untreated subjects: A Monte Carlo study. Stat Med 26: 734-753, 2007.

33. Marangoni G, O'Sullivan A, Faraj W, Heaton N and Rela M: Pancreatectomy with synchronous vascular resection-an argument in favour. Surgeon 10: 102-106, 2012.

34. Sgroi MD, Narayan RR, Lane JS, Demirjian A, Kabutey NK, Fujitani RM and Imagawa DK: Vascular reconstruction plays an important role in the treatment of pancreatic adenocarcinoma. J Vasc Surg 61: 475-480, 2015.
35. Barreto SG and Windsor JA: Justifying vein resection with pancreatoduodenectomy. Lancet Oncol 17: e118, 2016.

36. Yekebas EF, Bogoevski D, Cataldegirmen G, Kunze C, Marx A, Vashist YK, Schurr PG, Liebl L, Thieltges S, Gawad KA, et al: En bloc vascular resection for locally advanced pancreatic malignancies infiltrating major blood vessels: Perioperative outcome and long-term survival in 136 patients. Ann Surg 247: 300-309, 2008.

37. Turley RS, Peterson K, Barbas AS, Ceppa EP, Paulson EK, Blazer DG III, Clary BM, Pappas TN, Tyler DS, McCann RL and White RR: Vascular surgery collaboration during pancreaticoduodenectomy with vascular reconstruction. Ann Vasc Surg 26: 685-692, 2012.

38. Cheung TT, Poon RT, Chok KS, Chan AC, Tsang SH, Dai WC, Chan SC, Fan ST and Lo CM: Pancreaticoduodenectomy with vascular reconstruction for adenocarcinoma of the pancreas with borderline resectability. World J Gastroenterol 20: 17448-17455, 2014.

39. Jeong J, Choi DW, Choi SH, Heo JS and Jang KT: Long-term outcome of portomesenteric vein invasion and prognostic factors in pancreas head adenocarcinoma. ANZ J Surg 85: 264-269, 2015.

40. Elberm H, Ravikumar R, Sabin C, Abu Hilal M, Al-Hilli A, Aroori S, Bond-Smith G, Bramhall S, Coldham C, Hammond $\mathrm{J}$, et al: Outcome after pancreaticoduodenectomy for T3 adenocarcinoma: A multivariable analysis from the UK vascular resection for pancreatic cancer study group. Eur J Surg Oncol 41: 1500-1507, 2015.

41. Kulemann B, Hoeppner J, Wittel U, Glatz T, Keck T, Wellner UF, Bronsert P, Sick O, Hopt UT, Makowiec F and Riediger H: Perioperative and long-term outcome after standard pancreaticoduodenectomy, additional portal vein and multivisceral resection for pancreatic head cancer. J Gastrointest Surg 19: 438-444, 2015.

42. Wang WL, Ye S, Yan S, Shen Y, Zhang M, Wu J and Zheng SS: Pancreaticoduodenectomy with portal vein/superior mesenteric vein resection for patients with pancreatic cancer with venous invasion. Hepatobiliary Pancreat Dis Int 14: 429-435, 2015.

43. Beltrame V, Gruppo M, Pedrazzoli S, Merigliano S, Pastorelli D and Sperti C: Mesenteric-Portal vein resection during pancreatectomy for pancreatic cancer. Gastroenterol Res Pract 2015: 659730, 2015.

44. Fang JZ, Lu CD, Wu SD, Huang J and Zhou J: Portal vein/superior mesenteric vein resection in pancreatic cancer treatment in the elderly. Medicine (Baltimore) 96: e7335, 2017.

45. Prakash LR, Wang H, Zhao J, Nogueras-Gonzalez GM, Cloyd JM, Tzeng CD, Kim MP,Lee JE and Katz MHG: Significance of cancer cells at the vein edge in patients with pancreatic adenocarcinoma following pancreatectomy with vein resection. J Gastrointest Surg: Feb 28, 2019 Doi: 10.1007/s11605-019-04126-y (Epub ahead of print).

46. Murakami Y, Satoi S, Motoi F, Sho M, Kawai M, Matsumoto I and Honda G; Multicentre Study Group of Pancreatobiliary Surgery (MSG-PBS): Portal or superior mesenteric vein resection in pancreatoduodenectomy for pancreatic head carcinoma. Br J Surg 102: 837-846, 2015

47. Murakami Y, Uemura K, Sudo T, Hashimoto Y, Nakashima A, Kondo N, Nakagawa $\mathrm{N}$ and Sueda T: Benefit of portal or superior mesenteric vein resection with adjuvant chemotherapy for patients with pancreatic head carcinoma. J Surg Oncol 107: 414-421, 2013.

48. Shimada K, Sano T, Sakamoto Y and Kosuge T: Clinical implications of combined portal vein resection as a palliative procedure in patients undergoing pancreaticoduodenectomy for pancreatic head carcinoma. Ann Surg Oncol 13: 1569-1578, 2006.

49. Dang XW, Xu PQ and Ma XX: Splenocaval versus mesocaval shunt with artificial vascular graft for the treatment of Budd-Chiari syndrome. Hepatobiliary Pancreat Dis Int 4: 68-70, 2005.

50. Katayama Y, Minato N, Kawasaki H and Sakaguchi M: Surgical strategy for impending rupture of an infected anastomotic pseudoaneurysm of the aorta 9 years after a Bentall procedure: Radical surgery involving en bloc resection of the infected sternum, pseudoaneurysm, and artificial vascular graft. Gen Thorac Cardiovasc Surg 56: 584-588, 2008.

This work is licensed under a Creative Commons Attribution-NonCommercial-NoDerivatives 4.0 International (CC BY-NC-ND 4.0) License. 